\title{
REFLECTIVE TEACHING: INTERPRETING THE RESULTS OF PEDAGOGICAL SURVEYS AT HIGHER EDUCATION
}

\author{
N. Jesus-Silva ${ }^{1,2}$, C. Pereira ${ }^{2}$, N. Durão ${ }^{2}$, S. Sá ${ }^{3}$, C. Costa-Lobo ${ }^{1}$ \\ ${ }^{1}$ Universidade Portucalense Infante D. Henrique, Portucalense Institute for Legal Research \\ (PORTUGAL) \\ ${ }^{2}$ Universidade Portucalense Infante D. Henrique, Research on Economics, management and \\ Information Technologies (PORTUGAL) \\ ${ }^{3}$ Universidade do Minho, Centro de Investigação de Estudos da Criança da Universidade do \\ Minho (PORTUGAL)
}

\begin{abstract}
Obtaining feedback from students is an essential requirement of reflective teaching, allowing teachers to refine their practice. In the scope of the student evaluation of teaching effectiveness at higher education, in this article they are analyzed the constituent axes and the results of satisfaction survey in a Portuguese private institution of higher education, with the purpose of measure teaching effectiveness. The quantitative study was based on pedagogical surveys, one survey for each curricular unit attended by students at one Portuguese private higher education institution. A performance evaluation of a set of 68 teachers was made, in a full-time working regime, by students. Teaching activity is evaluated according to nine items using a 7-level Likert scale, in which level 1 represents the lowest and the 7 the highest. The following characteristics were also included in the study: gender, department, years of service in the institution, professional category, academic degree, work area, number of courses taught and annual school service, in number of hours. In this work are presented the results of exploratory and inferential analysis of student's answers to the survey applied in the year 2015-2016. Analyzes were made with the intention of verify if teacher's professional category, gender and years of service have influence on any of the items representatives of pedagogical skills. It is emphasized that whatever the semester, the professional category does not influence the pedagogical skills; gender and years of service of the teacher has no influence on the ability of the teacher to create conditions for the active participation of the students nor about the ability of the teacher to create a favorable climate for learning. This impact was evaluated for the two semesters in the 2015/2016 school year, using ANOVA one-way, MANOVA one-way and two-way parametric, correlation analysis-Pearson correlation and Reliability Analysis (Cronbach's Alpha). It is noteworthy, in the results, that the better the pedagogical skills, the better are their relationships with students. The results are discussed presenting contributions to the field of Institutional Management in Higher Education.
\end{abstract}

Keywords: Reflective teaching, teaching effectiveness, pedagogical surveys, Institutional Management in Higher Education.

\section{INTRODUCTION}

The improvement of the teaching-learning processes implies changes in the ways of teaching, learning and evaluating, reconstituting the roles of the teacher and the student. The reconstitution of these roles consists, in brief, of the teacher focusing on the teaching about the students' learning, and these actively participating, developing processes of reflection and self-evaluation of their competences (Costa-Lobo, Lopes, Pereira, Durão, Magalhães, 2017; Magalhães, Morais, Lopes, Freitas, Fernandes, Costa-Lobo, 2017). The perspective of unity and interaction in the domains of teaching, learning and evaluation changes the more traditional forms of teacher-centered teaching and learning evaluation, product-centric, summative and punctual, to other forms, subordinated to student participation in all stages of the teaching-learning process and evaluation. The importance of pedagogical training of the Higher Education Institutions (HEI) teachers is valued as a condition of improvement student learning. The lack of critical reflection that follows the flow of the teachinglearning process, that formative assessment could carried out, becomes an obstacle to the timely introduction of the necessary adjustments to plans and strategies used (Boud \& Falchikov, 2017; Crisp, 2012). To knowing the impact of the application of active learning methodologies in Higher Education Institutions (HEI) (Joyce, Weil \& Calhoun, 2017) requires not only the identification of the quality of skills learned through the analysis and interpretation of learning achievements of students, 
but also the knowledge of their effects on the future professional performance, by means of the perceptions of employers and professionals themselves ((Costa-Lobo, Lopes, Pereira, Durão, Magalhães, 2017; Magalhães, Morais, Lopes, Freitas, Fernandes, Costa-Lobo, 2017).

Since the main objective of higher education is to make students active, autonomous and responsible for their own learning, teachers should be able to promote and measure self-regulation processes and self-efficacy of students. The importance of assessment, self-assessment, regulation and selfregulation, to enhance learning determines the need to control the use and the quality of these processes by the meta-evaluation, towards a teaching-learning framework.

Knowing the impact of the application of active learning methodologies in HEl requires not only the identification of the quality of competences acquired through the analysis and interpretation of the students 'academic results, but also the knowledge of their effects on future professional performance through students' perceptions, employers and the professionals themselves. Given that the main objective of Higher Education is to make students agents active, autonomous and responsible for their own learning, teachers should be able to promote and evaluate students' self-regulation and encourage self-efficacy processes. The importance of evaluation, self-assessment, regulation and self-regulation, in order to improve learning, determines the need to control the use and quality of these processes through meta-evaluation, in the sense of a reference to the process of teaching and learning.

Jesus-Silva, Costa-Lobo, Pereira and Durão (2017) wrote that nowadays, it is assumed that the dynamic pedagogical evaluation of teachers is carried out, developing plural and multifaceted skills in teachers; as well as create a combination of efforts between people and between institutions, both in professional relationships and in interpersonal relationships to deal with emerging needs.

\section{METHODOLOGY}

The quantitative study was based on an online questionnaire (for each curricular unit attended by the student) with 3 sections to evaluate: the curricular unit (section 1), the teaching activity (section 2) and the student's performance in the curricular unit (section 3 ). It should be noted that all questions are of the closed type (Hill \& Hill, 2008).

The objective of this study is to analyze the performance evaluation of a set of 68 teachers (section 2), in a full-time working regime, teachers evaluated by students (average response rate of students in the 1st / 2nd year, $85.45 \%$ and $60.095 \%$, respectively).

Teaching activity was evaluated according to 9 items using a 7-level Likert scale, in which level 1 represents the lowest and the 7th highest.

The following characteristics were also included in the study: gender, department, years of service in the institution, professional category, academic degree, work area, number of courses taught and annual school service (in number of hours). This option allowed, besides the characterization of the teachers, to evaluate if these personal characteristics affect their performance. The procedures used for the treatment of the data were the descriptive analysis (frequency analysis, descriptive measures and association measures) and inferential analysis (ANOVA one-way, MANOVA one-way and twoway parametric, correlation analysis- Pearson correlation and Reliability Analysis (Cronbach's Alpha). The data were treated using the IBM SPSS Statistics 24.0 software.

\section{ANALYSIS AND DISCUSSION OF RESULTS}

Portucalense University (UPT) is a private higher education institution (HEI), located in Oporto, in the north of Portugal. More than acquiring theoretical knowledge, the students have the chance to develop practical work and research projects, developing different kinds of skills that prepare them for jobs in future career and for living in a competitive global society. Courses are structured so as to respond flexibly to changing labor market needs, through various teaching methods empirically based on significant case studies whenever applicable (Jesus-Silva et al., 2017).

UPT has its own dedicated staff and also counts on the input of practicing professionals from different industrial and commercial sectors, through the medium of guest seminars on various themes, thereby promoting its relationships with the corporate world with the goal of preparing students for future professional demands. Teachers with a teaching service at UPT are attached to the teaching service according to their scientific area. Of the set of 68 teachers studied, we found that the majority are 
female $(63.8 \%)$. It should be noted that $92.8 \%$ of these teachers are PhDs. Regarding the professional category, $96.6 \%$ are auxiliary teachers. It should also be noted that half of the full-time teachers teach at least 6 units annually, with an approximate average of 319 hours of school service. Finally, it should be noted that $68.1 \%$ of these teachers have been working for more than 3 years in this HEI, which shows great stability regarding the teaching staff.

The nine items, corresponding to the evaluation of the teacher's performance, carried out by the students, expressed their opinion for each teacher with regard to the curricular units attended, in each semester. Thus, for each semester, students evaluated whether the teacher used adequate teaching strategies and methodologies (item 1), showed clarity and ability to systematize the presentation of the subject (item 2), whether it was able to stimulate motivation and interest of the students (item 3), a favourable learning climate was created (item 4), conditions were created for the active participation of the students (item 5), materials were available to support the study (item 6), complied with the assessment rules agreed with the students (Item 7), there was a commitment to promote the quality of teaching (item 8), and finally, if the teacher showed availability for the clarification of questions (item 9).

It is important to point out that since each teacher was evaluated by a group of students from their curricular unit, then it makes sense to work with the average of the assessments obtained by each teacher for each of the items. Therefore, the items become quantitative variables.

For each item, the descriptive measures, mean $(\mathrm{m})$ and standard deviation $(\mathrm{sd})$ were calculated. It should be noted that for all these items, we observed that the average student scores were higher than 5, that is, above the "neutral" position (neither agreement nor student disagreement). Moreover, the standard deviations are reduced (ranging from 0.59 to 0.86 ) and are identical for all items, so that student evaluations are consistent. Therefore the average is a representative measure of the sample location and therefore we can conclude that the assessment of students, about the performance of teachers, is reliable and validates the high results of the evaluations. That is, the ability to stimulate students' motivation and interest (item $3,2^{\circ} \mathrm{S}$ ) was the item that presented the lowest average evaluation $(m=5.12, s d=0.84)$ and complied with the agreed assessment rules with students (item 7 , $\left.1^{\circ} \mathrm{S}\right)$ presented the highest average evaluation $(m=5.51, s d=0.59)$. Hence also, the overall average scores of teachers in the $1 \mathrm{st}$ and $2 \mathrm{nd}$ grades $(m=5.37, \mathrm{sd}=0.67$ and $m=5.21, \mathrm{sd}=0.85)$, respectively.

In order to evaluate the possible existence of association between two quantitative variables, a association measures was calculated: Pearson correlation coefficient $r$. Then, we performed the correlation analysis - Pearson correlation (after verification of the Normality assumption through the Kolmogorov-Smirnov test, with Lilliefors correction, for the variables involved) (Marôco, 2014).

To evaluate the effect of a qualitative independent variable (factor) on a quantitative dependent variable, we used the one-way ANOVA and, to evaluate the effect of one or more qualitative independent variables on more than one quantitative we used MANOVA. Parametric ANOVA and MANOVA require the simultaneous verification of two conditions, that is Normality of the quantitative variables (using the above test) and that the variances/covariances matrices of population are homogeneous (Levene test and M-Box test, in the case of ANOVA and MANOVA respectively) (Marôco, 2014).

Also we used Reliability Analysis (Cronbach's Alpha) to evaluate the existence of intern consistent of two indices created a posteriori (Murteira, Ribeiro, Silva, Andrade e Silva, Pimenta, \& Pimenta, 2015).

As the objective of this study is to evaluate the impact of pedagogical skills in pedagogical relationships, it is of interest only to analyze items 1 (adequate teaching strategies and methodologies), 2 (clarity and ability to systematize the presentation of the subject), 4 (create favorable learning climate) and 5 (create conditions for the active participation of the students). This impact will be evaluated for the two semesters, in order to verify if teacher's professional category, gender and years of service have influence on any of the items. This analysis begins by checking the applicability conditions of MANOVA by performing the 2 fundamental steps: test for Normality for the quantitative variables (items) and M-Box test for the homogeneity of covariance matrices. In addition, we must also evaluate the correlation between the items as well as the power of the test resulting from the comparison of the variables in the different groups (professional category, gender and years of service). Thus, to verify if the professional category (group) has influence in the student's appreciation of the use of adequate teaching strategies and methodologies (item 1) in the 1st and 2nd semester, the Normality assumption was verified as well as the hypothesis homogeneity of the covariance matrices ( $p$-value $=0,524>\alpha=0,05$ ). 
However, it is not appropriate to use MANOVA because, when evaluating the correlation between the variables, the value obtained for the Pearson correlation coefficient $(r=0.490)$ reveals a moderate association and also the power of the test resulting from the comparison of the two variables is low $(<0.5$ - is not acceptable). Therefore, according to Murteira, Ribeiro, Silva, Andrade e Silva, Pimenta, and Pimenta (2015), it is more appropriate to analyze the two variables under study through two ANOVA's (Tables 1 and 2).

Table 1- Adequate teaching strategies and methodologies $-1^{\text {st }}$ semester (ANOVA).

\begin{tabular}{lc|c|c|c|c} 
& \multicolumn{7}{c}{ ANOVA } & & \\
& Sum of Squares & $\mathrm{df}$ & Mean Square & $\mathrm{F}$ & Sig. \\
\hline Between Groups & 1,100 & 3 &, 367 &, 758 &, 522 \\
\hline Within Groups & 29,510 & 61 &, 484 & & \\
\hline Total & 30,610 & 64 & & & \\
\hline
\end{tabular}

It should be noted that the homogeneity of the variances was verified (Levene test: $p$-value $=0.892$ and $p$-value $=0.615$, respectively).

Table 2- Adequate teaching strategies and methodologies $-2^{\text {nd }}$ semester (ANOVA)

\begin{tabular}{lr|r|r|r|r} 
& \multicolumn{7}{c}{ ANOVA } & \multicolumn{1}{c}{ Sig. } \\
\hline Sum of Squares & df & Mean Square & \multicolumn{1}{c}{ F } & \multicolumn{1}{c}{ S } \\
\hline Between Groups & 2,316 & 3 &, 772 & 1,341 & \\
\hline Within Groups & 33,961 & 59 &, 576 & & \\
\hline Total & 36,277 & 62 & & & \\
\hline
\end{tabular}

The results obtained allow us to safely conclude that the professional category to which the teachers are related does not influence the student's appreciation of teaching strategies and methodologies (item 1) neither in the $1^{\text {st }}$ nor in the $2^{\text {nd }}$ semesters ( $p$-value $=0.522$ and $p$-value $=0.270$, both $>0.05$ ).

We then proceeded to find out if the professional category has influence on the student's appreciation of clarity and ability to systematize the presentation of the subject (item 2) in the 1st and 2nd semesters.

Again, it is not appropriate to use MANOVA because, when evaluating the correlation between the variables, the value obtained for the Pearson correlation coefficient $(r=0.492)$ only reveals a moderate association and also the power of the test resulting from the comparison of the two variables is low $<0.4$ - is not acceptable). So it is more appropriate to analyze the two variables under study through two ANOVAs (Tables 3 and 4).

Table 3- Clarity and ability to systematize the presentation of the subject - $1^{\text {st }}$ semester.

\begin{tabular}{lr|r|r|r|r} 
& \multicolumn{9}{c}{ ANOVA } & & \\
& Sum of Squares & df & Mean Square & F & \multicolumn{1}{c}{ Sig. } \\
\hline Between Groups &, 263 & 3 &, 088 &, 188 &, 904 \\
\hline Within Groups & 26,133 & 56 &, 467 & & \\
\hline Total & 26,396 & 59 & & & \\
\hline
\end{tabular}

Once again, the homogeneity of the variances (Levene test: $p$-value $=0.861$ and $p$-value $=0.510$, respectively) was verified. The results obtained allow us to conclude with certainty that the professional category to which the teachers are related does not influence the student's appreciation of clarity and ability to systematize the presentation of the subject (item 2) neither in the $1^{\text {st }}$ nor in the $2^{\text {nd }}$ semesters $(p$ - value $=0.904$ and $p$-value $=0.331$, both $>0.05)$. 
Table 4- Clarity and ability to systematize the presentation of the subject $-2^{\text {nd }}$ semester.

\begin{tabular}{lr|r|r|r|r} 
& \multicolumn{2}{c}{ ANOVA } & & \multicolumn{1}{c}{ Sig. } \\
\hline Sum of Squares & df & Mean Square & F & \multicolumn{1}{c}{, 321} \\
\hline Wetween Groups & 1,947 & 3 &, 649 & 1,192 & \\
\hline Tothin Groups & 32,127 & 59 &, 545 & & \\
\hline
\end{tabular}

As in the previous study, we verified that the semester did not influence the analysis of the professional category on item 1 nor on item 2, so we decided to evaluate if the professional category has influence on pedagogical skills (items 1 and 2).

We evaluated the possible existence of an association between items 1 and 2 for the first semester and concluded that there was a significant positive correlation $(r=0.987, p$-value $=0.000)$, so we chose to perform a MANOVA one-way.

M-Box test for the homogeneity of covariance matrices provided a p-value $=0.504>0.05$ therefore the applicability conditions are checked (the Normality hypothesis has already been checked back).

We can then confidently use the output Multivariate tests (Table 5).

Table 5- Multivariate tests (professional category (group/factor), dependent variables - item 1 and item 2) for $1^{\text {st }}$ semester.

\begin{tabular}{|c|c|c|c|c|c|c|c|}
\hline Effect & & Value & $\mathrm{F}$ & Hypothesis df & Error df & Sig. & $\begin{array}{l}\text { Noncent. } \\
\text { Parameter }\end{array}$ \\
\hline \multirow[t]{4}{*}{ Intercept } & Pillai's Trace &, 966 & $849,011^{b}$ & 2,000 & 60,000 &, 000 & 1698,021 \\
\hline & Wilks' Lambda & ,034 & $849,011^{b}$ & 2,000 & 60,000 &, 000 & 1698,021 \\
\hline & Hotelling's Trace & 28,300 & $849,011^{b}$ & 2,000 & 60,000 & ,000 & 1698,021 \\
\hline & Roy's Largest Root & 28,300 & $849,011^{b}$ & 2,000 & 60,000 &, 000 & 1698,021 \\
\hline \multirow[t]{4}{*}{ Categoria } & Pillai's Trace & ,065 & ,685 & 6,000 & 122,000 & ,662 & 4,108 \\
\hline & Wilks' Lambda & ,935 &, $680^{b}$ & 6,000 & 120,000 & ,666 & 4,079 \\
\hline & Hotelling's Trace & ,069 &, 675 & 6,000 & 118,000 & ,670 & 4,048 \\
\hline & Roy's Largest Root &, 060 & $1,217^{\mathrm{C}}$ & 3,000 & 61,000 & ,311 & 3,650 \\
\hline
\end{tabular}

We conclude that there are no significant differences ( $p$-value $\geq 0,311$ ) of the professional category factor on pedagogical skills.

Similarly, when we performed the same analysis in the second semester, we also obtained a very significant positive correlation $(r=0.981$, $p$-value $=0.000)$, M-Box test for the homogeneity of covariance matrices provided a p-value $=0,233>0,05$ therefore the conditions of applicability of MANOVA were validated. Thus, we can again use the output "Multivariate tests" with confidence, which allows us to conclude that there are no significant differences in the second semester ( $p$ value $\geq 0.3255$ of the professional category factor on pedagogical skills.

Finally, in order to understand whether gender and years of service influence the student's appreciation of the teacher's ability to create conditions for active student participation (item 5) and the ability to create favorable learning climate (item 4), we performed a MANOVA two-way (2 dependent variables - item 4 and item $5 ; 2$ groups / factors).

We concluded that there was a significant positive correlation $(r=0.986, p$-value $=0.000)$ between items. Normality assumption through the Kolmogorov-Smirnov test, with Lilliefors correction, for the variables involved was validated (Tables 6 and 7). 
Table 6- Tests of Normality (itens 4 and 5 by years of service).

Tests of Normality

Kolmogorov-Smirnov ${ }^{\mathrm{a}}$

\begin{tabular}{|c|c|c|c|c|c|c|c|}
\hline & Years of service & Statistic & $\mathrm{df}$ & Sig. & Statistic & $\mathrm{df}$ & Sig. \\
\hline \multirow[t]{4}{*}{ Item 5} & 1 & ,190 & 7 &, $200^{*}$ & ,929 & 7 &, 539 \\
\hline & 2 & ,223 & 8 & $200^{*}$ & ,871 & 8 & ,155 \\
\hline & 3 & , 138 & 6 & $200^{*}$ & ,979 & 6 & ,948 \\
\hline & More than 3 & 094 & 44 & ,200* & ,973 & 44 & ,378 \\
\hline \multirow[t]{4}{*}{ Item 4} & 1 & , 193 & 7 & ,200* & ,922 & 7 & ,482 \\
\hline & 2 & ,226 & 8 & $200^{*}$ & ,882 & 8 & , 198 \\
\hline & 3 & ,220 & 6 & $200^{*}$ & ,942 & 6 & ,673 \\
\hline & More than 3 & .111 & 44 & $200^{*}$ & 958 & 44 & 108 \\
\hline
\end{tabular}

*. This is a lower bound of the true significance.

a. Lilliefors Significance Correction

Table 7- Tests of Normality (itens 4 and 5 by years of service).

Tests of Normality

\begin{tabular}{l|l} 
Kolmogorov-Smirnov $^{\mathrm{a}}$ & Shapiro-Wilk
\end{tabular}

\begin{tabular}{l|l|l|r|r|r|r|r} 
& Gender & \multicolumn{1}{c|}{ Statistic } & \multicolumn{1}{c|}{ df } & \multicolumn{1}{c|}{ Sig. } & Statistic & \multicolumn{1}{c|}{ df } & \multicolumn{1}{c}{ Sig. } \\
\hline Item 5 & Female &, 107 & 42 &, $200^{*}$ &, 968 & 42 &, 273 \\
\cline { 2 - 9 } & Male &, 103 & 23 &, $200^{*}$ &, 973 & 23 &, 758 \\
\hline Item 4 & Female &, 139 & 42 &, 040 &, 951 & 42 &, 070 \\
\hline & Male &, 140 & 23 &, $200^{*}$ &, 957 & 23 &, 397 \\
\hline
\end{tabular}

*. This is a lower bound of the true significance.

a. Lilliefors Significance Correction

M-Box test for the homogeneity of covariance matrices provided a $\mathrm{p}$-value $=0.605>0.05$ so we can proceed to the analysis of the results of Multivariate tests (Table 8).

Table 8- Multivariate tests (gender and years of service (group/factor), dependent variables - item 4 and item 5) for $1^{\text {st }}$ semester.

\begin{tabular}{|c|c|c|c|c|c|c|c|}
\hline Effect & & Value & $\mathrm{F}$ & Hypothesis df & Error df & Sig. & $\begin{array}{l}\text { Noncent. } \\
\text { Parameter }\end{array}$ \\
\hline \multirow[t]{4}{*}{ Intercept } & Pillai's Trace &, 973 & $1025,454^{b}$ & 2,000 & 56,000 &, 000 & 2050,909 \\
\hline & Wilks' Lambda & ,027 & $1025,454^{b}$ & 2,000 & 56,000 & ,000 & 2050,909 \\
\hline & Hotelling's Trace & 36,623 & $1025,454^{b}$ & 2,000 & 56,000 &, 000 & 2050,909 \\
\hline & Roy's Largest Root & 36,623 & $1025,454^{b}$ & 2,000 & 56,000 &, 000 & 2050,909 \\
\hline \multirow[t]{4}{*}{ Gender } & Pillai's Trace & ,029 &, $829^{b}$ & 2,000 & 56,000 & ,442 & 1,658 \\
\hline & Wilks' Lambda & 971 &, $829^{b}$ & 2,000 & 56,000 & ,442 & 1,658 \\
\hline & Hotelling's Trace & ,030 & $829^{b}$ & 2,000 & 56,000 & ,442 & 1,658 \\
\hline & Roy's Largest Root & ,030 &, $829^{b}$ & 2,000 & 56,000 & ,442 & 1,658 \\
\hline \multirow[t]{4}{*}{ Years of service } & Pillai's Trace & ,040 & ,385 & 6,000 & 114,000 & ,888 & 2,308 \\
\hline & Wilks' Lambda & ,961 &, $379^{b}$ & 6,000 & 112,000 & ,891 & 2,271 \\
\hline & Hotelling's Trace & ,041 & ,372 & 6,000 & 110,000 & ,895 & 2,234 \\
\hline & Roy's Largest Root & ,028 &, $535^{\mathrm{c}}$ & 3,000 & 57,000 & ,660 & 1,604 \\
\hline \multirow{4}{*}{$\begin{array}{l}\text { Gender * Years of } \\
\text { service }\end{array}$} & Pillai's Trace & ,085 & ,844 & 6,000 & 114,000 &, 539 & 5,063 \\
\hline & Wilks' Lambda & ,916 &, $837^{\mathrm{b}}$ & 6,000 & 112,000 &, 544 & 5,023 \\
\hline & Hotelling's Trace & ,091 & ,830 & 6,000 & 110,000 &, 549 & 4,982 \\
\hline & Roy's Largest Root &, 076 & $1,437^{\mathrm{C}}$ & 3,000 & 57,000 & ,242 & 4,311 \\
\hline
\end{tabular}


As all p-values are high we can conclude that:

- There is no interaction between gender and years of service;

- There is no significant interaction between the factors under study for any of the quantitative variables, that is, the gender and years of service of the teacher, have no influence on the capacity of the teacher to create conditions for the active participation of the students (item 5) and on the capacity of the teacher to create a favorable learning climate (item 4).

Carrying out the same type of analysis for the second semester, we also found a very significant positive correlation $(r=0.989$, $p$-value $=0.000)$, as well as the validity of Normality and the covariance matrix equality (M-Box test for the homogeneity of covariance matrices provided a $p$-value $=0.453>$ 0.05 ). The results provided presented $p$-values $>0.01$, so we again reached the same conclusions as those obtained for the first semester.

Finally, in order to verify if the variability of the answers resulted from the differences between the students evaluations, we performed a reliability analysis to verify the existence of internal consistence measured by Cronbach's Alpha. The value of alpha varies from 0 to 1 and higher values of alpha are more desirable.

Table 9 shows the results of Cronbach's Alpha for evaluate two dimensions which are "Pedagogical skills" (dimension 1- items 1 and 2 for both semesters) and "Pedagogical relations" (dimension 2items 4 and 5 for both semesters). As can be observed, the Cronbach's Alpha coefficients for both dimensions lies between 0,8 and 0,9 which is considered good (Murteira, Ribeiro, Silva, Andrade e Silva, Pimenta, \& Pimenta, 2015).

Therefore, both dimensions in this study were deemed to be reliable.

Table 9 - Cronbach's Alpha coefficients.

\begin{tabular}{lcc}
\hline Dimension & Cronbach's Alpha & N of Items \\
\hline 1. Pedagogical skills & 0,887 & 4 \\
2. Pedagogical relations & 0,874 & 4 \\
\hline
\end{tabular}

As Cronbach's Alpha coefficients for both dimensions shown a good intern consistency, we can continue the analysis by building two indices constituted by the arithmetic average of the variables which constitute each dimension. So, we created the indices, "mean_D1" e "mean_D2" which summarize the information given by the variables which integrate them and represent the respective average score. In order to identify if there was a relationship between the indices "mean_D1" and "mean_D2" we calculate Pearson correlation coefficient. Correlation analysis confirms the significant positive relationship $(r=0,991)$ at the 0,01 level (2-tailed), that is, the better the pedagogical skills of teachers, the better their pedagogical relationships with students

\section{CONCLUSIONS}

For this sample of teachers we can say that:

- Whatever the semester, the professional category does not influence the pedagogical skills.

- Whatever the semester, neither the gender nor the years of service of the teacher has influence on the ability of the teacher to create conditions for the active participation of the students nor about the ability of the teacher to create a favorable climate for learning.

- The better the pedagogical skills of teachers, the better their pedagogical relationships with students.

Strong impact of good pedagogical skills in pedagogical relationships? This question then makes sense: to what extent is it important to be competent as a teacher (pedagogical skills / scientific skills) to establish good pedagogical relationships?

In an attempt to respond to future work and in agreement with other authors:

The importance of pedagogical training of the HEI teachers is valued as a condition of improvement student learning (Ashwin, 2009). The lack of critical reflection that follows the flow of the teaching- 
learning process, that formative assessment could carried out, becomes an obstacle to the timely introduction of the necessary adjustments to plans and strategies used (Sá, 2015).

To knowing the impact of the application of active learning methodologies in HEI requires not only the identification of the quality of skills learned through the analysis and interpretation of learning achievements of students, but also the knowledge of their effects on the future professional performance, by means of the perceptions of employers and professionals themselves (Boud \& Falchikov, 2017; Biggs, 2003; Wu \& Jesson, 2018).

\section{REFERENCES}

[1] Ashwin, P. (2009). Analysing Teaching Learning Interaction in Higher Education: Accounting for Structure and Agency. London: Continuum.

[2] Biggs, J. (2003). Teaching for Quality Learning at University. Buckingham: The Society for Research into Higher Education e Open University Press.

[3] Boud, D. \& Falchikov, N. (2017)). Aligning assessment with long-term learning. Assessment \& Evaluation in Higher Education, 31(4), 399-413.

[4] Costa-Lobo, C., Lopes, F. C., Pereira, C. S., Durão, N, \& Magalhães, M. (2017). Human Interaction Skills and Employability at Information Technology Internships. In Paulo Alberto da Silva Pereira, Osman Titrek, \& Gozde Sezen- Gultekin (Eds.), Proceedings of 3rd International Conference on Lifelong Education and Leadership for All (pp. 105-114). Porto (Portugal). ISBN: 978-605-66495-2-3.

[5] Crisp, G. (2012). Integrative assessment: reframing assessment practice for current and future learning, Assessment \& Evaluation in Higher Education, 37(1), 33-43.

[6] Hill, M., Hill, A. (2008). Investigação por questionário. Edições Sílabo.

[7] Jesus-Silva, N., Costa-Lobo, C., Pereira, C.S., \& Durão, N.S. (2017). Evaluation of teaching performance in Higher Education: Students perspectives and teaching management indicators. In 11th annual International Technology, Education and Development Conference INTED2017 Proceedings (pp. 4565-4571), 6th-8th March 2017, Valencia, Spain.

[8] Joyce, B., Weil, M., \& Calhoun, E. (2017). Models of Teaching. (9a ed.). Boston: Pearson.

[9] Marôco, J. (2014). Análise estatística com o SPSS Statistics (6 $6^{\mathrm{a}}$ edição). ReportNumber. (Marôco, 2014).

[10] Magalhães, M., Morais, P., Lopes, F., Freitas, I., Fernandes, S., \& Lobo, C.C. (2017). Transitions from higher education to labour market: Observatory of internships in business organizations. In 11th annual International Technology, Education and Development Conference INTED2017 Proceedings (pp. 6451-6459), 6th-8th March 2017, Valencia, Spain. ISBN: 978-84-617-8491-2 / ISSN: 2340-1079.

[11] Murteira, B., Ribeiro, C. Silva, J., Andrade e Silva, J., Pimenta, C., \& Pimenta, F. (2015). Introdução à estatística ( $3^{\mathrm{a}}$ Edição). Escolar Editora.

[12] Sá, S. (2015). Ensino, Aprendizagem e Avaliação no Ensino Superior: Perspetivas e Práticas. Tese de doutoramento, não publicada. Universidade do Minho, Braga.

[13] Wu, Q. \& Jessop, T. (2018). Formative assessment: missing in action in both research-intensive and teaching focused universities? Assessment \& Evaluation in Higher Education, 43, 7, 10191031. 